\section{Las pinturas murales del convento \\ franciscano de San Gabriel, Cholula}

Ligia

Fernández Flores

CEPE-UNAM
INTRODUCCIÓN

Uno de los temas que mayor interés ha suscitado entre los especialistas del arte virreinal en México, es el relacionado con la pintura mural del siglo XVI debido a que en dicha manifestación artística - entre otros aspectos - se puede estudiar y reflexionar en torno a la forma en que posiblemente los indígenas pudieron asimilar las formas y técnicas artísticas procedentes del mundo europeo. Por ello, el objeto de este trabajo es realizar un breve acercamiento artístico a algunas de las pinturas murales que aún se conservan en el claustro del convento franciscano de San Gabriel en Cholula, ciudad localizada en el actual estado de Puebla, ya que fue uno de los conjuntos conventuales más importantes durante dicha centuria en la zona Puebla-Tlaxcala.

\section{ANTECEDENTES}

Durante la época prehispánica, Cholula fue un importante centro religioso, político y económico. En el Preclásico (ca. 1200 a.C.- 200 d.C.) estuvo ocupada por pobladores de diversa filiación étnica hasta la llegada de los teotihuacanos. Hacia 750-800 d.C. la región fue dominada por los olmecaxicalancas, grupo étnicamente heterogéneo compuesto por pueblos nahuas, mixtecos y chocho-popolocas, quienes lograron establecer un control absoluto en las regiones de Cholula, Tlaxcala y probablemente Chalco-Amaquemecan. ${ }^{1}$

Con la desintegración de la antigua ciudad de Tollan, (actualmente Tula, Hidalgo), hacia el 1156 d.C., un grupo de filiación tolteca-chichimeca se estableció en Cholula, en donde quedaron reducidos a servidumbre por los olme-
1 Xavier Noguez, "La zona del Altiplano central en el Posclásico: la etapa tolteca", en Linda Manzanilla y Leonardo López Luján, coordinadores, Historia Antigua de México, vol. III, p. 209. 
2 Luis Reyes, "La zona del Altiplano central en el Posclásico: la etapa chichimeca", en Manzanilla y López, op. cit., vol. III, p. 246. No obstante, se recomienda la consulta desde pp. 245-251.

3 Fray Diego Durán, Historia de las Indias de Nueva España e islas de tierra firme, t. I, cap. $X X, 13, p .180$. Después de la conquista española, los cholultecas conservaron su fama de buenos comerciantes, siendo particularmente importante su comercio de grana cochinilla, cacao y textiles. Vid. también René Acuña, Relaciones Geográficas del siglo XVI: Tlaxcala, t. II, [núm. 5], (Serie Antropológica 59), pp. 143-144.

4 Se recomienda consultar la interesante descripción que hace fray Diego Durán de las ceremonias realizadas por los cholultecas a esta divinidad, Durán, op. cit., t. I, cap. VI, pp. 61-69 y cap. XIX, 4, p. 170. También se destaca la importancia de este dios para la región Puebla-Tlaxcala, vid. fray Gerónimo de Mendieta, Historia Eclesiástica Indiana, libro II, cap. V, p. 82; cap. VII, p. 86; cap. X, pp. 91-93 у cap. XVIII, pp. 104-105. Asimismo, consideramos importante destacar que uno de los informantes que Durán consultó para cuestiones religiosas era cholulteca "AI cual, rogándole me alumbrase de algunas cosas para poner en esta mi obra, me preguntó que de qué materia quería me tratase. Yo, como me topé con lo que deseaba, le dije que desde el principio del mundo, en lo que a su generación indiana tocaba y tenía noticia”, vid. Durán, op. cit., t. II, cap. I, 19, pp. 16-17. 5 Mendieta, op. cit., libro III, cap. XLIX, p. 309. La misma alusión la encontramos ca-xicalanca, que como ya mencionamos, dominaban la región poblano-tlaxcalteca. Sin embargo, hacia 1292 los toltecas se rebelaron de sus opresores, se apoderaron del gobierno de Cholula y posteriormente realizaron alianzas militares con otros siete grupos chichimecas para conquistar las regiones ocupadas por los grupos olmecas. Una vez que los olmecas fueron desplazados "[...] los toltecas de Cholula entablaron alianzas matrimoniales con sus aliados chichimeca concediéndoles grandes extensiones de tierra". ${ }^{2}$

En el ámbito económico, la región se dedicaba al comercio con las zonas costeras del Golfo de México y hacia el sur con el valle de Oaxaca, 1legando incluso a controlar las rutas comerciales en esas regiones. Un ejemplo de este activo comercio fue su famoso y renombrado mercado, en donde se podían adquirir joyas, piedras preciosas y plumas. ${ }^{3}$ Asimismo, en el ámbito religioso Cholula fue un importante centro de peregrinación debido al culto a Quetzalcóatl, dios del viento. En efecto, al estallar los conflictos religiosos que habían motivado la huída del gobernante-sacerdote Ce Ácatl Topiltzin Quetzalcóatl de Tula, su primer refugio fue la ciudad de Cholula, por lo que el culto a la deidad adquirió mayor importancia, propiciando con ello que este centro se convirtiera en la sede de una poderosa teocracia que logró dominar la zona, pues no sólo los cholultecas le rendían especial veneración a esta divinidad, sino también los pueblos circunvecinos. ${ }^{4}$ No sorprende por ello que durante el siglo XVI su fama perdurara y que algunos cronistas hicieran alusión a la ciudad de Cholula como "[...] el santuario de toda la tierra, como otra Roma $[\ldots]^{\prime \prime}$

En el siglo XIV, con la llegada de otros grupos chichimecas - entre ellos los mexicas - a la zona del Altiplano Central, su paulatino fortalecimiento y su expansión territorial, la creación de la Triple Alianza de la que formaron parte, así como el interés por dominar a los señoríos de la región Puebla-Tlaxcala, propiciaron una serie de conflictos que todavía continuaban a la 1legada de los españoles en el siglo XVI. ${ }^{6}$

Con el arribo de las tropas españolas a las costas del actual estado de Veracruz en 1519 y durante su trayecto hacia la renombrada ciudad de México-Tenochtitlan, Hernán 
Cortés decidió pasar por Cholula, pese a los informes proporcionados por los tlaxcaltecas respecto a que los cholultecas eran aliados de los mexicas. Al 1legar a la ciudad, Cortés fue cordialmente recibido, aunque muy pronto los cholultecas se negaron a proporcionar alimento a las tropas españolas. Temiendo un ataque sorpresivo, Cortés mandó encerrar en el templo a los señores principales y al tiempo que se ejecutaban estas medidas los españoles se percataron de que algunas calles de la ciudad habían sido cerradas y se habían hecho fosos para que los caba1los no pudieran galopar. Ante estos indicios de peligro, Cortés increpó a los principales su traición y ordenó su ejecución; asimismo, infiriendo la inminente rebelión de los cholultecas también ordenó el ataque de los españoles contra toda la población, ataque que culminó con una terrible matanza y cuyo resultado fue que Cholula quedó sometida a partir de ese momento. Posteriormente y de acuerdo con el relato de fray Diego Durán, los cholultecas junto con los huexotzincas y tlaxcaltecas, entre otros grupos indígenas, ayudarían a Cortés a conquistar la ciudad de México-Tenochtitlan. ${ }^{7}$

Consumada la conquista de México, Cholula continuó siendo un importante centro económico y religioso, aunque paulatinamente sería desplazado por la naciente ciudad de Puebla. En efecto, Francisco de la Maza señala que la reedificación de Cholula fue muy lenta, debido principalmente a que los cholultecas fueron uno de los grupos requeridos para edificar la ciudad angelopolitana, ya que sus numerosas construcciones requirieron una gran cantidad de mano de obra indígena que prestara este servicio. Sin embargo, es necesario destacar que dada su importancia, a Cholula le fue concedido el título de ciudad desde 1537 por cédula de Carlos V y el escudo de armas le fue otorgado el 19 de junio de $1540 .^{8}$

Es necesario destacar que durante el proceso de conquista militar y posterior aculturación de los indígenas, una práctica común fue la destrucción sistemática de los antiguos edificios públicos y teocallis prehispánicos con la finalidad de reutilizar los materiales para la construcción de las nuevas ciudades trazadas por los españoles. No obstante, dichas acciones tuvieron también un caracter legitimador de la conquista, ya que a través de este también en fray Juan de Torquemada, Monarquía Indiana, 1969, (Biblioteca Porrúa, 41-43), vol. 2, libro dieciséis, cap. XXVIII, p. 203.

6 Vid. María Concepción Obregón, “La zona del Altiplano central en el Posclásico: la etapa de la Triple Alianza", en Manzanilla y López, op. cit., vol. III, pp. 284-290, particularmente los enfrentamientos con los señoríos de Huejotzingo y Tlaxcala. También se recomienda lo mencionado por Robert Ricard, La conquista espiritual de México, (Sección de Obras de Historia), p. 88 y Durán, op. cit., t. II, cap. XLII, 6 , p. 324, en donde menciona que Cholula y otras provincias aledañas “ estaban enemistadas con México y nunca las habían podido sujetar y siempre tenían guerras y enemistades; aunque, por otra parte, decían que no las querían sujetar, a causa de que los soldados tuviesen donde se ejercitar y que fuesen ocasión de las guerras para que cada uno procurase ganar honra y dignidades en la milicia". Sin embargo, el mismo cronista describe más adelante un enfrentamiento entre mexicas y cholultecas, en donde se demuestra la fuerza militar de los últimos. Ibid., cap. LIX, pp. 447-449.

7 Durán, op. cit., t. II, cap. LXXIV, 3, pp. 539-540 у сар. LXXVII, pp. 562-563.

8 Francisco de la Maza, La Ciudad de Cholula y sus iglesias, pp. 38-39. 
9 lbid., p. 38

10 Torquemada, op. cit., libro tercero, cap. XIX, vol. I, p. 282. Vid. también Acuña, op. cit., pp. 121-145, en donde se consigna la relación de la ciudad de Cholula que realizó el corregidor Gabriel de Rojas en 1581, así como el magnífico plano elaborado para esta relación. proceso se consolidó tanto el dominio político de la Corona Española en los nuevos territorios, como la supremacía espiritual del catolicismo sobre las religiones mesoamericanas.

Durante el proceso anteriormente descrito Cholula no fue la excepción, ya que de acuerdo con Francisco de la Maza en dicha ciudad:

Lo primero arrasado fue el templo de Quetzalcóatl, dando los terrenos a los franciscanos para que edificasen su convento. Después se construirían las Casas Reales y luego las casas de los pocos vecinos españoles en el centro y las de los indios alrededor, así como capillas sobre los viejos teocallis, con las mismas piedras fabricadas. Sin embargo, para 1549 debió tener ya un aspecto muy de ciudad española, pues fue escogida Cholula, y no Puebla, para las importantes pláticas políticas entre don Antonio de Mendoza, el virrey saliente, y don Luis de Velasco, el nuevo virrey $[\ldots]^{9}$

Por otra parte, Torquemada, al referirse a la ciudad de Cholula la describió de la siguiente manera:

Eran los edificios de estas insignes casas, de cal, y canto, y no sè de cierto, si por entonces usaban el ladrillo; pero sè decir, que aora son todas sus portadas de èl, y mui blanqueadas de cal, y yeso. Tienese por mui cierto, y averiguado, que tenia tantos templos, como dias tiene el Año. Avia en cada uno de ellos, una torre, y en algunos, dos, y mui altas. De estas torres se contaron en su principio cuatrocientas, y sobre todas era señalada la de el Templo Mayor. Vèr por defuera esta Ciudad, viniendo de Tlaxcallan, y de otras partes, que pueda descubrirse, era de grandisima recreacion, por estar tan torreada, almenada, y cercada de tan vistosos, y hermosos edificios. Sus calles fueron, y son de las mejores, asi en ancho, como en largo, de cuantas Ciudades tiene el Mundo no tuercen en ninguna manera, si no que comienzan derechas, y acaban con el mismo orden, que comenzaron; y aun aora, que no debe de tener siete mil vecinos (y faltandole la hermosura de aquellos sus grandes templos, y torres, que memoria de todo esto no ha quedado) parece tan linda, y tan ordenada, que es de recreación descubrirla por cualquier parte, que se parezca, por sus buenos edificios, aunque todos bajos, y mucha frescura de arboleda, con que está adornada $[\ldots]^{10}$ 
EL CONVENTO Y LA IGLESIA FRANCISCANA DE SAN Gabriel ChOlula

El convento de San Gabriel probablemente ya existía hacia 1529, pues para esa fecha, en la Información solicitada por la primera Audiencia de México, aparece consignado como guardián del monasterio fray Alonso Xuárez. ${ }^{11}$ Noticias posteriores nos informan que para 1531 se encontraban cuatro frailes radicando en el monasterio de esta ciudad y en 1534 y 1537 fray Toribio de Benavente "Motolinía" pasó ahí las temporadas de cuaresma confesando a los indígenas de Cholula. A pesar de estas noticias que atestiguan su importancia, seguramente este primer convento debió ser de modestas proporciones y de materiales pobres como adobe, tierra y paja, ya que como bien señala Francisco de la Maza "Una cosa es fundar un convento y otra es edificarlo". ${ }^{12}$

Será hasta el año de 1549 que se empiece a construir la iglesia, la cual fue concluída y dedicada el 30 de abril de 1552, de acuerdo con una inscripción que había en el arco del coro y que actualmente se ha perdido. Por las fechas anteriormente referidas, Toussaint ${ }^{13}$ atribuye este monasterio a Toribio de Alcaraz, arquitecto que por orden del virrey don Antonio de Mendoza había realizado la traza de diversos conventos novohispanos, siendo quizá Cholula uno de los primeros en los cuales se ensayó el modelo proyectado por este insigne arquitecto. A propósito de la importancia del convento de Cholula, Mendieta señala lo siguiente con relación a los establecimientos que se querían fundar hacia 1567: "Mas si en algún pueblo de los que ahora tenemos a cargo hubiere de hacerse otra casa de nuevo, por no ser suficiente la vieja, en tal caso puédese hacer a la traza de la de Cholula". ${ }^{14}$

Para 1581, el corregidor de la ciudad de Cholula Gabriel de Rojas describió de la siguiente manera el convento de San Gabriel:

Hay en esta ciudad un monasterio de LA ORDEN DEL SEÑOR SAN FRAN[CIS]CO, muy suntuoso y bien labrado, así la iglesia dél como la casa y claustros de los religiosos. Tienen un hermoso retablo principal, sin [mencionar] cuatro colaterales buenos, que costó más de diez mil p[es]os. Residen ordinariamente en él veinte religiosos, porque
11 De la Maza, op. cit., p. 61. La información que a continuación se glosa, también fue tomada de este autor, salvo que se indique lo contrario.

12 Ibid., p. 62.

13 Manuel Toussaint, Arte Colonial en México, 5a. ed., pp. 39 y 42 . De acuerdo con lo señalado por Francisco de la Maza, Manuel Toussaint en su obra Arquitectura del siglo $X V I$, en el volúmen VI de "Iglesias de México" fue el primero en consignar las fechas de construcción del monasterio, aunque sin indicar la procedencia de sus fuentes. Francisco de la Maza, en su estudio ya citado, menciona que Toussaint seguramente retomó esta información de un manuscrito que perteneció a Federico Gómez de Orozco y que corresponde a una Relación dela fundación del convento de Cholula, escrita por fray Blas de la Torre quizá a mediados del siglo XVII y que de la Maza reproduce en un apéndice documental. Vid. de la Maza, op. cit., pp. 139-149. 14 De la Maza, op. cit., p. 63. 
15 Acuña, op. cit., p. 144. Vid. también Antonio de Ciudad Real, Tratado curioso y docto de las grandezas de la Nueva España, edición, estudio, apéndices, glosarios, mapas e índices de Josefina García Quintana y Victor M. Castillo Farreras, t. I, pp. CXLII, 85, aunque en esta última referencia no queda claro si el cronista se refiere al convento franciscano de Tlaxcala o Cholula.

16 Antonio Rubial, La hermana pobreza. El franciscanismo: de la Edad Media a la evangelización novohispana, p. 149 .

17 Mendieta, op. cit., libro IV, cap. XVII, p. 423. hay estudio de Gramática. Aquí administran los sacramentos a los indios y españoles, porque no hay otra parroquia ni iglesia en esta ciudad. Este monasterio se fundó luego que se descubrió esta tierra y, porque el gran concurso de los naturales no cabía en esta iglesia, hicieron junto a ella, dentro de su mismo circuito, una capilla grande casi en cuadra, con dos torres a los lados, fundada sobre muchos arcos. Y, estando ya acabada de bóveda, para celebrar una fiesta solemne en ella, le quitaron las cimbrias de los arcos y bóvedas, y aquella noche, después de celebrada la fiesta, como la obra estaba tierna, dio en el suelo toda la bóveda, sin quedar más que las paredes $[\ldots]^{15}$

Un aspecto relevante que debemos destacar, es que en este convento el estudio de la gramática fue de gran importancia y significación, ya que durante el siglo XVI, más que en ningún otro siglo:

El estudio de los idiomas indígenas era un medio necesario para llevar a cabo una evangelización eficaz y en este sentido era considerado como un conocimiento humano que ayudaba a realizar una labor divina [...] El dominio de las lenguas nativas por parte de los frailes es fácilmente demostrable al ver la gran cantidad de obras realizadas por ellos: gramática o artes, vocabularios, doctrinas, sermonarios, confesionarios y traducciones de vidas de santos y de secciones del Evangelio y de las epístolas de san Pablo. Los franciscanos escribieron casi el ochenta por ciento de los textos que conocemos en lenguas indígenas del siglo XVI. Gracias a ellos se alfabetizaron muchos de esos idiomas, con lo cual han podido ser estudiados por los lingüistas desde el siglo pasado. ${ }^{16}$

En este sentido y como más adelante referiremos, algunos de los frailes de esta orden, cuyos retratos se encuentran pintados en el claustro de este convento, fueron excelentes lingüistas y predicadores.

Por otra parte, también es importante señalar que la solvencia económica de la ciudad no sólo permitió mantener su monasterio, sino que de acuerdo con lo consignado por Mendieta:

La devoción y limosnas del pueblo de Cholula no se pueden ponderar. Los años atras por la mayor parte se sustentaba el convento de S. Francisco de los Ángeles (que es ciudad de españoles) con las sobras del monesterio de Cholula, con morar de ordinario en el de Cholula mas de treinta frailes, y acullá otros tantos, y aun mas. ${ }^{17}$ 
En la actualidad el conjunto religioso conserva una buena parte de sus dependencias, entre las que destacan su gran atrio, el convento, la iglesia, las capillas posas y la gran capilla abierta, mejor conocida como Capilla Real o de Indios. La iglesia se encuentra ubicada de oriente a poniente, de acuerdo con el sentido simbólico tradicional en occidente. El templo es de una sola nave, sin crucero, dividida en cinco tramos; al igual que otras iglesias de las órdenes mendicantes, sus muros son sumamente gruesos, sostenidos por recios contrafuertes y coronados con almenas y merlones. En su interior se encuentra recubierto con una techumbre de nervaduras góticas, siendo más complicada la decoración de la bóveda del presbiterio. ${ }^{18}$

En el exterior la iglesia tiene dos portadas, la principal y la lateral denominada como en otras iglesias franciscanas, de la Porciúncula. Diego Angulo describió ambas portadas de la siguiente manera:

Las dos portadas son renacentistas. En la de los pies el vano de ingreso aparece encuadrado por las pilastras y el entablamento. En la superficie lisa de sus jambas dos medallones con los anagramas "Ihs" y "Xsp" [...] El rico marco circular del óculo completa el conjunto. En la portada lateral el entablamento descansa en columnas abalaustradas. E1 arco de medio punto está formado por grueso toro estriado en espiral que continúa en las jambas e incluso en los pedestales. En el deseo de prestarle mayor riqueza, no contento con las formas del plateresco, cubre la rosca del arco con el tronco y la cinta enrrollada, el típico motivo del gótico de los Reyes Católicos. ${ }^{19}$

A esta descripción, Francisco de la Maza añade 1o siguiente con relación a la decoración de la portada principal:

[los anagramas inscritos en la puerta] son de Cristo, van en latín y en griego [...] En las bases de las pilastras van los de María y José y macetones renacentistas muy finamente labrados. En el capitel de las pilastras, enmedio, es digna de verse una saliente granada, abierta por cuatro lados y mostrando los ricos granos de su interior [...] La hermosa ventana se decora, en su marco inicial, con motivos tomados, según parece de la heráldica o de la numismática, esto es, las columnas de Hércules con el plus ultra y unos roleos que las unen en forma de S. De este anillo se va rehundiendo, en finas molduras hasta atravesar el muro y formar el vano circular que ilumina el coro [...] Termina la
18 Para una comprensión más clara y detallada de los elementos y significados simbólicos de los conjuntos conventuales vid. Elena Isabel Estrada, "Sentido político, social y religioso en la arquitectura conventual novohispana", en Historia del Arte Mexicano. Arte Colonial I, 2a. ed., vol.5, pp. 624-643.

19 Diego Angulo, Historia del Arte Hispanoamericano, t. II, pp. 211-212. Debemos aclarar que estas iniciales no son anagramas sino monogramas. Agradezco la observación a la maestra Raquel Pineda Mendoza. 
20 De la Maza, op. cit., pp. 66-67. El mismo autor menciona otros detalles no referidos en la cita que nosotros anotamos, por lo que se recomienda ampliamente su descripción y apreciaciones.

21 Elena Isabel Estrada, "La pintura mural durante el Virreinato", en Historia del Arte Mexicano. Arte Colonial III, 2a. ed., vol. 7, pp. 1012-1013. fachada en triángulo, a modo de frontón, coronada aún de sus antiguas y esbeltas almenas [...]. La puerta lateral es la llamada de Porciúncula, más rica en ornamentación que la mayor. "Corresponde - según Angulo - a un momento posterior en la evolución del plateresco: es obra de gran claridad, pero de estilo tan puramente peninsular que se creería de una iglesia andaluza; la encuadran columnas abalaustradas, medallones decoran sus enjutas y candeleros y trofeos cubren jambas y arco". En las filacterias de las columnas lleva trozos de salmos muy difíciles de leer y en el extradós del arco dice, en latín la promesa que hizo Cristo a San Francisco de que todos sus hijos serían salvos, justamente en la aparición de la Porciúncula $[\ldots]^{20}$

\section{EL CLAUSTRO CONVENTUAL Y SUS PINTURAS}

El programa pictórico del claustro fue ideado, al igual que en muchos otros claustros:

[...] en estrecha adecuación con los edificios que los recibirían; es decir, el sentido simbólico-litúrgico de las dependencias del recinto conventual habría de determinar muchas veces la temática de los murales. Si el claustro corresponde simbólicamente al paraíso y a la esencia de la vida monacal, los temas afines a estos significados son los de la Vida y Pasión de Cristo [...] Los ciclos de la vida de santos fundadores o los árboles genealógicos de las órdenes son también temas propicios [...] los martirologios tampoco son raros en la decoración pictórica claustral $[\ldots]^{21}$

Es importante destacar este sentido simbólico-litúrgico de los claustros conventuales novohispanos, pues los ciclos pictóricos en ellos representados también estuvieron vinculados con el proceso de evangelización de los indígenas recién conversos a la religión católica, ya que cumplieron una función didáctica al mostrar, a través de imágenes, muchos de los temas considerados más significativos para determinada orden religiosa, pues ejemplificaban los modelos de comportamiento y santidad al cual debían aspirar tanto los frailes como los neófitos. En este sentido, la pintura mural del claustro del convento de San Gabriel que aún se conserva corresponde a los siguientes temas y se encuentra distribuida de la siguiente manera: 
a) Claustro alto:

"La misa de San Gregorio": Representa el momento en el cual San Gregorio celebraba misa y uno de los asistentes dudó de la presencia de Cristo en la hostia. En ese instante y por la plegaria dirigida por el santo, Cristo apareció en el altar rodeado con los instrumentos de su pasión. Esta leyenda piadosa surgió en Roma y es posterior al siglo XIII, ${ }^{22}$ ya que de acuerdo con Réau:

Las indulgencias que los papas atribuyeron a las imágenes de esta escena milagrosa, explican su prodigiosa difusión entre los siglos XV y XVI. El tema se hizo popular a causa de los romeros, los peregrinos que hacían el camino de las siete basílicas de Roma, y también por la escultura funeraria y la imaginería piadosa. ${ }^{23}$

"San Sebastián". E1 santo se encuentra representado al momento de ser atormentado por primera ocasión, por lo que su cuerpo se representa cubierto de flechas. San Sebastián, oriundo de las Galias había ingresado al ejercito del emperador Carino, con la finalidad de proteger a los cristianos. Al ser descubierto y denunciado fue conducido ante el emperador Diocleciano, sucesor de Carino en el trono, quien 1o condenó a ser asaeteado en el Campo Marte. La ejecución se llevó a cabo y sus verdugos lo creyeron muerto, sin embargo fue rescatado por una viuda de nombre Irene, quien logró salvarle la vida. Una vez recuperado, Sebastián se presentó nuevamente ante Diocleciano para reclamarle su crueldad con los cristianos, por lo cual el emperador lo sentenció nuevamente a muerte, aunque ordenó que lo mataran a palos en el circo y su cadáver fuera arrojado a la Cloaca Máxima. ${ }^{24}$ San Sebastián cobró una gran popularidad durante la Edad Media, ya que no sólo fue considerado como el tercer patrón de Roma (después de San Pedro y San Pablo) sino que también se le atribuyó poderes contra la peste. Asimismo "Tal como ocurriera con san Francisco de Asís, sus devotos 1legaron a asimilarlo a Jesucristo. El árbol al que lo ataron se comparaba con la cruz de Jesús, y sus cinco heridas con las 1lagas de Cristo". ${ }^{25}$
22 Louis Réau, Iconografía del arte cristiano. Iconografía de los Santos, G-O, t. 2, vol. 4, p. 53.

23 Ibid.

24 Louis Réau, Iconografía del arte cristiano. Iconografía de Ios Santos, P-Z/ Repertorios, t. 2, vol. 5, pp. 193-194. Vid. también Héctor Schenone, Iconografía del Arte Colonial. Los santos, vol. II, p. 716. 25 Réau, op. cit., t. 2, vol. 4, p. 194.

\section{"Santo"(no identificado)}


26 Schenone, op. cit., vol. I, p. 343.

27 Ibid., p. 345. b) Claustro bajo:

"La coronación de la Virgen". Representa el momento en el cual la Santísima Trinidad la corona después de su asunción al cielo.

"San Francisco ante el crucificado": Una vez que San Francisco había decidido cambiar de vida, entró en cierta ocasión a la iglesia de San Damián, la cual se encontraba casi en ruinas. Al arrodillarse frente el crucifijo que allí se veneraba, escuchó una voz procedente de la cruz que le dijo en tres ocasiones: "Francisco, repara mi casa, que como ves, está a punto de arruinarse toda ella". San Francisco entendió que la orden hacía referencia a la reconstrucción de la iglesia e inmediatamente se dirigió a su casa, tomó sin permiso unos paños que serían vendidos por su padre Pedro Bernardone y se dirigió a Foligno, en donde no sólo obtuvo dinero por los paños, sino también por vender un caballo. Acto seguido, se dirigió a la iglesia de San Damián y entregó el producto de su venta al sacerdote para que reconstruyera el templo. Éste, temiendo una represalia por parte del padre de Francisco se negó a aceptarlo, motivo por el cual el santo arrojó el dinero por la ventana. Sin embargo, el sacerdote accedió a que Francisco se quedase a vivir con él. ${ }^{26}$

"San Francisco se despoja de sus vestiduras ante el obispo de Asís": Debido a que Francisco había tomado y vendido los paños sin el consentimiento de su padre para entregar el dinero en la iglesia de San Damián, Pedro Bernardone decidió castigarlo y lo encadenó en su casa mientras él salía de viaje. Sin embargo, su madre lo liberó y Francisco rápidamente huyó de la casa paterna. Indignado, Bernardone se presentó ante el obispo para que éste obligara a Francisco a pagar esta deuda. Ante esta situación, el santo devolvió lo poco que tenía, se quitó sus vestiduras y quedando en total desnudez se las entregó a su padre. ${ }^{27}$

"San Francisco en el carro de fuego": Un sábado por la noche, estando el santo en oración, sus compañeros vieron 
como penetraba un carro de fuego con un globo luminoso en el cobertizo donde oraba Francisco. Todos quedaron maravillados ante el suceso y también notaron que la luz que irradiaba les permitía percibir la conciencia de los demás. (En muchas obras artísticas el globo es reemplazado por la figura del santo). ${ }^{28}$

"San Francisco ante el papa Honorio III": Hay dos momentos en la vida del santo en los cuales se entrevistó con el papa Honorio III: la primera fue hacia 1217 cuando en un viaje a Roma el santo acudió a solicitarle la protección de su orden. En esa ocasión la corte pontificia quedó admirada por la elocuencia con la que se expresó, elocuencia que él mismo atribuyó a la inspiración del Espíritu Santo. Durante la segunda entrevista, San Francisco le solicitó dicho personaje la aprobación de una tercera regla (con anterioridad había realizado otras dos, mismas que fueron rechazadas por sus compañeros debido a la austeridad manifiesta en ellas). Con relación a esta petición se hizo manifiesto "[...] la disconformidad del papa en aceptarla, pues la juzgaba muy austera, a lo que el santo se opuso insistiendo en que él sólo había escrito lo que Cristo mismo le había dictado, por lo cual el pontífice la convalidó", lo cual sucedió el 29 de diciembre de $1223 .^{29}$

\section{c) Claustro bajo:}

Retratos de frailes distinguidos de la orden franciscana. Los retratos se encuentran enmarcados en cartelas manieristas y son policromados. Los frailes cuyos nombres quedaron registrados son los siguientes: fray Diego de Cañizares; fray Rodrigo de Ayamonte; fray García de Salvatierra; fray Juan Osorio, fray Miguel Navarro; fray Pablo de la Cueva; fray Juan Roldán; fray Pedro Goz; fray Domingo de Aréyzaga; fray José de Sanstia; fray Juan de Romanones y fray Juan de Bastida. ${ }^{30}$

Basándonos en lo consignado por fray Jerónimo de Mendieta, tenemos las siguientes noticias sobre algunos de ellos:
28 lbid., p. 350

29 Ibid., pp. 365, 381-382.

30 De la Maza, op. cit., p. 71. Los temas de las pinturas que estamos reseñando fueron tomados de la referencia de este autor. Sin embargo, omitió mencionar los restos de pintura mural con los temas correspondientes al "San Francisco en el carro de fuego" en el claustro bajo, el santo no identificado del claustro alto, así comolos dos personajes con arcos a cada uno de los lados del San Sebastián. Quizá cuando él escribió su estudio, estas escenas todavía se encontraban encaladas. 
31 Mendieta, op. cit., libro V, pte. I, cap. LIV, pp. 707-708.

32 Ibid., libro IV, cap. XLII, pp. $542,544$.

33 Ibid., libro V, pte. I, cap. XIII, p. 597.
Fray Juan Osorio. Fue descendiente de una importante familia de Ocaña en Toledo. Llegó por primera vez a la Nueva España en compañía del virrey Antonio de Mendoza, aunque él no era un fraile profeso. Regresó a España, pero por una orden de Carlos V se le ordenó volver a las Indias. En Sevilla, conoció a Jacobo de Testera, a fray Francisco de Bustamante y a fray Francisco de Toral, a quienes solicitó 1o aceptaran como fraile lego. Llegó como novicio a la Nueva España en 1542, profesando poco tiempo después en el convento de San Francisco de México donde ejerció el cargo de sacristán por muchos años, dando ejemplo de humildad y dedicación. Una vez que dejó el cargo de sacristán se dedicó a la oración y contemplación. Murió en 1581 y fue enterrado en el Convento Grande de la Ciudad de México. ${ }^{31}$

Fray Miguel Navarro. Fue elegido decimocuarto provincial de la Provincia del Santo Evangelio de México en 1567 y fue el decimosegundo comisario de la misma provincia en 1573. Dedicó sus esfuerzos a mejorar "[...] edificios de iglesias y casas, porque apenas hay alguna buena en que su diligencia y cuidado no haya tenido parte en la comenzar, proseguir ó acabar". Mendieta destacó en particular las obras que este personaje realizó para el convento franciscano de los Ángeles, en donde no sólo llevó a término la iglesia, sino también la dotó de otros ornamentos. ${ }^{32}$ El mismo cronista relató que él acompañó al padre Navarro a Tlalmanalco en 1567, recién elegido éste como provincial. Ahí ambos decidieron ir a la tumba de fray Martín de Valencia, misma que encontraron vacía, pues el cuerpo del religioso había desaparecido inexplicablemente. ${ }^{33}$

Fray Juan de Romanones. Natural de un pueblo del mismo nombre en Toledo, vino a México siendo un fraile profeso y acompañado del eminente fray Francisco de Tembleque, constructor del famoso acueducto que condujo agua a la región de Otumba. Romanones permaneció entre los indígenas por más de cuarenta años y en ese tiempo aprendió la lengua mexicana; predicó, compuso sermones, tratados y tradujo al náhuatl fragmentos de la Biblia, mismos que fueron de gran utilidad a los predicadores en 
la catequización de los indígenas. Fue guardián del convento franciscano de Otumba, cuando murió fue enterrado en el convento de San Gabriel en Cholula. ${ }^{34}$

Fray Juan de Bastida. Procedía de la región de Extremadura y llegó a la Nueva España hacia 1550. A pesar de no contar con grandes estudios,

[...] por su vida ejemplar y celo ferventísimo de la observancia de su profesion, fue diversas veces electo en definidor y guardian de México y de otras casas principales de la provincia [...] Supo la lengua mexicana en breve tiempo, luego como vino de España, y en ella trabajó fielmente por espacio de cuarenta años, confesando y predicando á los indios y instruyéndolos en cristianas costumbres hasta que el Señor fué servido de llevarlo para sí [...]

Fue enterrado en el convento de San Francisco de la capital novohispana. ${ }^{35}$

Fray Domingo de Areizaga. Desde pequeño se educó en la ciudad de Victoria, donde también realizó su profesión en el convento de San Francisco. Pasó a la Nueva España en 1554, en donde fray Francisco de Toral lo llevó a Tecamachalco para que aprendiera la lengua de los popolocas, misma que fue asimilada por este fraile en corto tiempo. Posteriormente

[...] fué enviado al estudio, donde comenzando desde los primeros rudimentos de la gramática latina, hasta concluir el curso de la sagrada teología, salió en pocos años tan buen letrado, que por su suficiencia en letras, acompañada con la perfeccion de su religiosa vida, los prelados superiores le encomendaron en veces la visita de otras provincias, y en esta del Santo Evangelio fué difinidor y provincial en dos veces [...] en la lengua bárbara que aprendió, fué de los que mejor la supieron, y en ella trabajó muchos años confesando y predicando y rigiendo en lo espiritual á los nuevos convertidos. ${ }^{36}$

Mendieta destacó no sólo su celo, sino también su profunda humildad y bondad. Murió cuando ocupaba el cargo de guardián en convento de San Francisco de México y en sus exequias estuvieron presentes el virrey y dos obispos, siendo enterrado en la capilla de San José. ${ }^{37}$
34 Ibid., libro III, cap. LIX, p. 350; libro IV, cap. XLIV, pp. 551-552; libro V, pte. I, cap. LI, pp. 696-697.

35 Ibid., libro V, pte. I, cap. LIV, p. 711.

36 Ibid., libro V, pte. I, cap. LV, pp. 712-713.

37 Ibid., pp. 713-714. 
38 Ibid., libro V, pte. I, cap. LVII, p. 721

39 Ibid., pp. 719-725

40 Es importante señalar que tanto Diego Angulo como Manuel Toussaint aceptaron la fecha de 1530 para la elaboración de estas pinturas, quizá por no relacionar esta fecha tan temprana con la de la construcción de la iglesia. Cfr. Angulo, op. cit., t. II, p. 355 y Manuel Toussaint, Pintura Colonial en México, 3a. ed., p. 26.

41 George Kubler, Arquitectura Mexicana del Siglo XVI, 2a. reimp., pp. 440-441. De la Maza retomó lo afirmado por Kubler y atribuyó este error a la intervención que sufrieron las pinturas en el siglo XIX, señalando que al momento de que las obras fueron retocadas, debieron de confundir la fecha de 1530 por la de 1580 . Vid. de la Maza, op. cit., p. 70.
Fray García de Salvatierra. Profesó en España y fue enviado por sus superiores a la isla de Santo Domingo. Posteriormente se trasladó a la Nueva España y en la provincia del Santo Evangelio de México residió en diversos conventos, siendo en el de Toluca donde vivió más años sirviendo principalmente como portero. Mendieta refirió lo siguiente con relación a este personaje:

Era Fr. García tan pobre en el uso de las cosas, tan abstinente, humilde, sufrido y mortificado, y tan perfecto en toda virtud, que desde que pasó á estas partes, de todos los que lo conocieron y conversaron, siempre fué tenido por hombre santo, verdadero imitador del padre S. Francisco. ${ }^{38}$

Entre sus numerosas virtudes destacaban sobre todo la caridad, la obediencia y los arrobos que le acometían, aunque también Mendieta refirió en otros pasajes de la vida de este fraile el caracter casi milagroso de muchos de ellos. ${ }^{39}$

Ahora bien, a pesar de la fecha de 1530 inscrita en la pintura mural "San Francisco se despoja de sus vestiduras ante el obispo de Asís", los autores que se han ocupado de su estudio coinciden en señalar que se trata de una fecha que no corresponde con su elaboración, pues como ya anotamos líneas arriba, al menos la iglesia se estaba edificado hacia $1549-1552 .{ }^{40}$ Con relación a este problema, Kubler señaló que el estilo avanzado de las obras, así como los objetos representados corresponden a una fecha posterior a 1530. Asimismo, este autor también consideró que las pinturas presentan ciertos rasgos que recuerdan al Atlas Durán y las obras del claustro de Tepeapulco e indica que en España hacia 1530

[...] encontramos poca referencia a las formas clasicistas y platerescas de estos paneles. Las ilustraciones de libros de la época (ca. 1530), además de los grabados españoles en madera, ostentaban aún la influencia de los modelos góticos del norte, influencia que perduró hasta después de la mitad del siglo. Por lo tanto, resulta difícil aceptar una fecha anterior para el estilo tan avanzado de estos murales; sería mucho más coherente ubicarlos en el tercer cuarto del siglo. ${ }^{41}$

Por su parte, María Ester Ciancas no descartó la apreciación hecha por Kubler y de la Maza, sin embargo anotó la 
posibilidad de que la fecha pudiera ser 1550, argumentando que la construcción del claustro pudo realizarse paralelamente a la erección de la iglesia. Asimismo podríamos decir que contraria a la apreciación de Kubler, esta autora consideró que el estilo predominante de las pinturas tiene un marcado caracter medieval. ${ }^{42}$

Otro de los autores consultados fue Constantino Reyes Valerio, quien sin referirse concretamente a las pinturas de Cholula ni a un estilo en particular, propone que los ciclos pictóricos murales de los grandes conjuntos conventuales debieron pintarse en la primera mitad del siglo XVI o poco antes de la segunda gran epidemia de 1576, (la primera fue en 1546-1547) debido precisamente a que la población fue terriblemente diezmada por estas dos catástrofes. $^{43}$

Ahora bien, con relación a la cuestión de atribuir la elaboración de las obras a pintores españoles o indígenas, el problema resulta más complicado. Ya Kubler había planteado la dificultad de definir, a través del estilo, la identificación del trabajo indígena o europeo en las pinturas realizadas para los grandes conjuntos conventuales del siglo XVI. Asimismo, consideró prácticamente imposible atribuirlas a cualquiera de estos dos grupos por la carencia de fuentes, aunque llegó a considerar la posibilidad de la intervención del trabajo indígena - sobre todo por la temática - en murales como los de Ixmiquilpan y Culhuacán. ${ }^{44}$

Por otra parte, la mayoría de los autores que consultamos coinciden en afirmar que las obras del convento de San Gabriel fueron realizadas por pintores indígenas, debido a la "ingenuidad" y dificultad con que fueron elaboradas: de la Maza retomó lo dicho por Manuel Toussaint sobre la sencillez de las escenas, aunque no atribuyó directamente su realización a la mano de obra indígena. ${ }^{45}$ Para Felipe Pardinas:

En las < pinturas > del convento de Cholula, tanto en la representación del Despojamiento de las Vestiduras por San Francisco de Asís ante el Obispo, como en la de La Entrevista de San Francisco con el Papa Honorio III, los caracteres indígenas aparentes en ellas son notorios. ${ }^{46}$
42 Cfr. María Ester Ciancas, El arte en las iglesias de Cholula, pp. 149-151.

43 Constantino Reyes Valerio, Arte Indocristiano, p. 383 y ss

44 Cfr. Kubler, op. cit., pp. 443-448.

45 De la Maza, op. cit. p. 73.

46 Felipe Pardinas, "El arte Mesoamericano del siglo XVI", en Cuarenta siglos de plástica mexicana. Arte Colonial, p. 107. 
47 Ciancas, op. cit., p. 149.

48 Reyes Valerio, op. cit., pp. 369-457.

49 lbid., pp. 381-382.
Por su parte, Ciancas señaló que:

[...] el carácter de los grandes temas pintados que antes mencionamos es predominantemente medieval. Ello es debido en gran parte al primitivismo y sencillez que emanan de estas obras, marcadas por la limitada habilidad del artista o artistas que las 1levaron a cabo; es muy probable que las realizaran pintores indígenas, tlacuilos, quienes se estaban iniciando en el arte occidental, de conceptos tan distintos a los precolombinos. ${ }^{47}$

En fechas más recientes, Constantino Reyes Valerio se dió a la tarea de confirmar estas apreciaciones, realizando un exhaustivo y sistemático estudio de las crónicas de los siglos XVI y XVII, confrontando muchas de estas fuentes con lo analizado en autores como Toussaint y Kubler. ${ }^{48}$ En su opinión y de acuerdo con los testimonios vertidos principalmente por los frailes, gracias al entrenamiento y al aprendizaje realizado en las escuelas especializadas y en los mismos conventos de las tres grandes órdenes fue posible que los pintores indígenas adquirieran las habilidades necesarias para realizar la pintura mural en los diversos conventos. Asimismo, no duda en afirmar 1o siguiente:

El hecho de pintar miles y miles de metros cuadrados obliga a pensar en los medios de que se valieron los frailes para dar cima a esta obra, que así considerada, por necesidad cambia los puntos de vista a partir de los cuales se ha valorado la pintura mural. Uno de ellos tiene que ser definitivo: que los pintores españoles no intervinieron porque apenas si hubo uno que otro antes de mediar el siglo y varios años después eran unos cuantos. Además, los misioneros no iban a esperar con los brazos cruzados a que viniesen artistas europeos para empezar la representación de los temas religiosos que necesitaban para enseñar la doctrina en sus conventos...Por otra parte, recurrir a pintores españoles o extranjeros hubiera significado costos enormes que hubieran repercutido más aún en las comunidades indígenas, ya tan agobiadas por los tributos y gastos para construir los monasterios. ${ }^{49}$

Asimismo, este autor intentó demostrar cómo la habilidad indígena superó los obstáculos del aprendizaje occidental, aunque refutó de manera tajante las opiniones de algunos autores que insisten en señalar que la pintu- 
ra mural con "errores" de perspectiva, dibujo y defectos anatómicos debe ser atribuida a los tlacuilos indígenas o a pintores hispanos anónimos, sin que se enfrente y analice el problema desde otros puntos de vista, como el económico o religioso que hemos citado líneas arriba. ${ }^{50}$

Acorde con los planteamientos expuestos por Constantino Reyes Valerio, nosotros también nos inclinamos a sugerir que los ciclos pictóricos de este convento fueron realizados por un equipo de pintores indígenas. Esta hipótesis puede sustentarse a través de dos referencias consignadas en 1581 por el ya mencionado corregidor de Cholula, Gabriel de Rojas, quien con relación a las actividades que desarrollaron los habitantes de la ciudad menciona lo siguiente:

Los naturales della son personas hábiles, de ingenio, bien inclinadas a las cosas de doctrina y, en los of[ici]os que aprenden, muestran mucha agilidad, y son grandes mercaderes, labradores, hortelanos, jardineros y pintores, y usan los demás of[ici]os mecánicos que los españoles usamos. ${ }^{51}$

Asimismo, cuando el corregidor describió las construcciones de la ciudad, anotó lo siguiente:

Las casas están edificadas, y se labran hoy, al modo que labran los españoles: de piedra tosca, ladrillo y adobe, cubiertas de azoteas encaladas [...] Tienen las salas y aposentos, que son más pequeños que los que labran españoles, bien adornados por de dentro, lucidos con cal y con una tierra amarilla lustrosa, y con historias pintadas, o colgados y esterados con petates muy pintados. Y no hay casa donde no haya un altar con muchas imágenes de santos. Todas las aceras q[u]e miran a las calles están labradas de ladrillo, que es una buena vista, $\mathrm{y}$, en general, es la mejor casería [sic] de indios que hay en toda la Nueva España: junto con estar las calles tan bien trazadas y derechas como un juego de ajedrez, no hay en todo el pueblo sola una teja. La madera y tablazón se traen del monte de Tlaxcalla y, la cal, de la ciudad de los Ángeles, aunque para la iglesia y comunidad, tienen sus canteras cerca de la ciudad de los Ángeles, de donde traen la piedra y, en hornos que dentro desta ciudad tienen, la cuecen. ${ }^{52}$

Ambas referencias nos confirman, por una parte, que no sólo había en la ciudad de Cholula artesanos diestros
50 Ibid., p. 404 y ss.

51 Acuña, op. cit., p. 126. Las cursivas son mías.

52 Ibid., p. 142. Las cursivas son mías. 
53 Santiago Sebastián, lconografía e Iconología del Arte Novohispano, p. 64. en los oficios enseñados por los españoles, y en el caso que nos interesa, pintores, oficio que debió de haber sido importante para que en las casas, por modestas que fueran, tuvieran pinturas como decoración. Por otra parte, el hecho de que el monasterio contara con sus propias canteras para la extracción de cal, nos confirma que los frailes pudieron disponer de este material tan necesario para la construcción y decoración de su conjunto conventual.

Por lo anteriormente señalado y entrando propiamente en el análisis estilístico podemos decir que en las ocho grandes escenas principales del convento de San Gabriel, el artista o los artistas a quienes se encomendaron las obras debieron utilizar grabados europeos como modelos, ya sea en forma literal o parcial, lo cual fue una práctica muy común en el ambiente artístico de la época, tanto en Europa como en América y que en el caso de los artistas indígenas también se convirtieron en un medio a través del cual aprendieron las formas de representación plástica occidental. Sin embargo, es poco probable que utilizaran grabados con las pinturas referentes a los frailes eminentes de la orden, ya que éstos retratos obedecen a tipos humanos más convencionales que pueden apreciarse en ciclos pictóricos de otros conventos y no a modelos grabados como fuente de inspiración. Con relación a la técnica, es patente la utilización clara y precisa de las líneas que sirven de contorno y conforman a los personajes, lo que seguramente nos refiere una copia podríamos decir "textual" de la línea, así como la posible utilización de calcas para delinear las figuras sobre los muros.

Respecto a los temas que representan, Santiago Sebastián señaló que las pinturas realizadas para el claustro de San Gabriel tienen un programa "[...] netamente franciscano en diferentes niveles: cristológico, mariano y franciscano propiamente dicho $[\ldots]^{\prime \prime}{ }^{53}$ Este programa seguramente obedeció al deseo de los frailes de plasmar, a través de estas escenas, el ideal evangélico original, basado principalmente en la imitación de la vida de Cristo, sus apóstoles y santos, por ello:

El asemejarse a Jesús debía ser el máximo anhelo del franciscano y su pobreza, su afán misionero y su mismo martirio debían guiar su vida [...] Esta actitud de imitación debía hacerse extensiva a los apóstoles y a los santos, en especial a 
san Francisco. Ellos que eran simples mortales habían desarrollado en su vida lo que Cristo había enseñado y vivido, y eran, por esto, excelentes ejemplos para encontrar el camino de la perfecta imitación del Maestro. ${ }^{54}$

Así, en "La misa de San Gregorio" se ha representado simbólicamente la unión de la ceremonia eucarística con la Pasión de Cristo. ${ }^{55}$ En esta escena podemos apreciar la inclusión de cinco personajes (dos diáconos, dos subdiáconos y San Gregorio al centro), Cristo desnudo y coronado de espinas que aparece sobre el altar de pie y rodeado con las insignias de su Pasión. A pesar de la frontalidad de la escena, podemos apreciar la intención de crear y sugerir zonas espaciales en profundidad, marcadas en primer plano por las divisiones en donde se arrodillan los personajes y sobre la mesa, por la colocación de los objetos, particularmente el sepulcro de donde emerge la figura del Redentor. Por otra parte, en esta escena notamos la constante utilización de líneas curvas para crear efectos de volúmen en los ropajes.

Con relación a la pintura de "San Sebastián", la figura del santo es un tanto ingenua, debido particularmente a cierto grado de incorrección anatómica, escaso modelado y por el exceso de flechas que tiene clavadas. Estos aspectos no dejan de ser singulares, ya que contrariamente a los ideales renacentistas de belleza y corrección con los que se suele representar este tema, el San Sebastián de este claustro parece estar más acorde con resaltar el martirio al cual es sometido por dos arqueros, que a mostrar la belleza anatómica del personaje. Este énfasis en el martirio podría reforzar la idea de que las obras realizadas para este convento tenían un claro sentido didáctico y devocional que hemos anotado líneas arriba.

En la escena "San Francisco ante el crucificado", el santo se encuentra arrodillado, levantando la cabeza y juntando las manos en señal de oración, mientras recibe el mensaje que Cristo le dirige: "VADE FRANCISCE. REPARA DOMVM. MEAM" ("Ve Francisco y repara mi casa"). Esta inscripción casi cubrió el nombre del santo, el cual también se encuentra escrito a la altura de su cabeza: "SAN FRA[NCI]SCO." En esta escena apreciamos que Cristo en la cruz tiene un caracter protagónico, no sólo por la monumentalidad de sus formas, sino también por

54 Rubial, op. cit., p. 103.

55 De la Maza, op. cit., p. 72.

Asimismo, este autor realizó un análisis formal de las escenas de "La Misa de San Gregorio", "San Sebastián” y las tres relativas a los pasajes de la vida de San Francisco. Ibid., pp. 72-73. 
la intensidad dramática que emana, así como por el vuelo de los paños de su cendal. A pesar de lo sumario de su anatomía, existe una clara intención de naturalismo, presente sobre todo en el modelado y sombreado de ciertas partes de su cuerpo, particularmente el marcar ciertas líneas para sugerir los músculos de las piernas. Lo mismo que en la escena relativa a la misa, volvemos a encontrar la sugerencia de planos espaciales, a través de pequeños montículos creados a partir de pinceladas gruesas, largas y poco cuidadas, así como por la sugerencia del celaje representado como si fuera realizado a base de "emborronamientos".

En las escenas en donde San Francisco se despoja de sus vestiduras y su entrevista con el papa Honorio III, podemos apreciar como el artista, quizá en busca de un cierto naturalismo, representó a las figuras en posición casi frontal y claramente delineadas. Sin embargo, debido sobre todo a la dificultad para realizar el espacio, notamos que los pequeños montículos, al igual que las respectivas sillas del obispo y del papa nos introducen a él, aunque la pared de fondo contrarresta el efecto, lo mismo que la planimetría de las figuras, las cuales consiguen cierto volúmen en el sombreado de los rostros y en los ropajes simulando pliegues. En las dos escenas es claro cómo el obispo y el papa adquieren un carácter predominante en la composición, ya que ambas figuras, en un afán de frontalidad, adoptan proporciones monumentales y antinaturales. Por otra parte, cuando Francisco se despoja de sus vestiduras, la figura del santo también presenta una postura antinatural, particularmente evidente en la incorrecta flexión del cuerpo y en la desarticulación de sus miembros (torso y piernas). Si bien es cierto que estas incorrecciones pueden obedecer a la poca habilidad y a la dificultad de representar correctamente las posturas corporales por parte del artista o los artistas que llevaron a cabo el trabajo, podríamos pensar que también se encuentran en función de lograr una claridad expositiva. 


\section{CONCLUSIONES}

A través de este breve análisis tratamos de destacar que las pinturas murales del convento franciscano de San Gabriel en Cholula han sido motivo de interés por parte de algunos especialistas del Arte Novohispano, quienes han expresado distintos puntos de vista en torno a la realización de los ciclos pictóricos de este convento.

En términos generales y tratando de llevar a cabo una revisión historiográfica, hemos citado las opiniones vertidas por algunos estudiosos como María Ester Ciancas y Felipe Pardinas quienes atribuyen la autoría de las obras a pintores indígenas debido a su carácter "primitivo, ingenuo y sencillo". Estos juicios, que desafortunadamente continuan teniendo vigencia en algunos círculos académicos, se han venido modificando en los últimos años gracias a nuevas investigaciones e interpretaciones que descartan la validez de juicios de valor tan tajantes en torno a una problemática que es sumamente compleja, ya que a pesar de las aportaciones realizadas por numerosos investigadores dedicados al estudio de la pintura mural del siglo XVI (como algunos otros que también citamos en este trabajo), el problema de filiación estilística de las obras, tanto a pintores indígenas como españoles, es una problemática que continúa discutiéndose, en espera de que fuentes documentales, bibliográficas y estudios comparativos multidisciplinarios (de historiadores, historiadores del arte, arquitectos, restauradores, etc.) nos permitan conocer algun día la autoría de dichas pinturas.

Por otra parte, creemos que para tener una visión más integral y completa de los ciclos iconográficos plasmados en los muros conventuales, es necesario realizar una investigación más acuciosa y profunda, tanto de las crónicas novohispanas del siglo XVI, como la búsqueda de fuentes grabadas que pudieran haber servido de modelos para la realización de las pinturas. Consideramos también que el estudio de ambos aspectos, vinculados con el de las obras escritas por los padres y doctores de la iglesia, teólogos y escritores místicos, redundará en una mejor comprensión de las mismas. 


\section{BIBLIOGRAFÍA}

ACUÑA, René, Relaciones Geográficas del siglo XVI: Tlaxcala. México, IIA-UNAM, 1985, t. II. [número serial 5] (Serie Antropológica 59)

ANGUlo IÑIgueZ, Diego, Historia del Arte Hispanoamericano. Barcelona, Salvat, 1950, t. II.

CiAnCAS, María Ester, El arte en las iglesias de Cholula. México, SEP, 1974. (SEP-SETENTAS 165)

Ciudad Real, Antonio de, Tratado curioso y docto de las grandezas de la Nueva España. Edición, estudio, apéndices, glosarios, mapas e índices de Josefina García Quintana y Victor M. Castillo Farreras. México, IIH-UNAM, 1993. (Serie Historiadores y Cronistas de Indias/6)

DURÁN, fray Diego, Historia de las Indias de Nueva España e islas de la tierra firme. México, Porrúa, 1967, 2 vols. (Biblioteca Porrúa, 36, 37)

ESTRADA DE GERLERO, Elena I., "Sentido político, social y religioso en la arquitectura conventual novohispana", en Historia del Arte Mexicano. Arte Colonial I, 2a. ed. México, SEP/Salvat, 1986, vol. 5, pp. 624-643.

-, "La pintura mural durante el Virreinato" en Historia del Arte Mexicano. Arte Colonial III, 2a. ed. México, SEP/ Salvat, 1986, vol. 7, pp. 1011-1027.

KubLER, George, Arquitectura Mexicana del Siglo XVI, 2a. reimp. México, FCE, 1990.

MAZA, Francisco de la, La Ciudad de Cholula y sus iglesias, México, IIE-UnAm, 1959. (Estudios y Fuentes del Arte en México, IX)

MENDIETA, fray Gerónimo de, Historia Eclesiástica Indiana. 2a. ed. facsimilar, México, Porrúa, 1971. (Biblioteca Porrúa, 46) Noguez, Xavier, "La zona del Altiplano central en el Posclásico: la etapa tolteca", en Linda Manzanilla y Leonardo López Luján, coords., Historia Antigua de México. México, INAH/unam, Miguel Ángel Porrúa, 1995, vol. III, pp. 189-224.

OBRegón Rodríguez, María Concepción, "La zona del Altiplano central en el Posclásico: la etapa de la Triple Alianza", en Linda Manzanilla y Leonardo López Luján, coords., Historia Antigua de México. México, INAH/unAm, Miguel Ángel Porrúa, 1995, vol. III, pp. 265-306. 
PARDINAS, Felipe, "El arte Mesoamericano del siglo XVI", en Cuarenta siglos de plástica mexicana. Arte Colonial. México, Herrero, 1970.

RICARD, Robert, La conquista espiritual de México. México, FCE, 1986. (Sección de Obras de Historia)

RÉAU, Louis, Iconografía del arte cristiano. Iconografía de los santos, G-O. Barcelona, Ediciones del Serbal, 1997, t. 2, vol. 4. (Cultura Artística 7)

- Iconografía del arte cristiano. Iconografía de los santos, P-Z/Repertorios. Barcelona, Ediciones del Serbal, 1998, t. 2, vol. 5 (Cultura Artística 8)

REYES GARCíA, Luis y Lina Odena Güemes, "La zona de1 Altiplano central en el Posclásico: la etapa chichimeca", en Linda Manzanilla y Leonardo López Luján, coords., Historia Antigua de México. México, INAH/UnAM/Miguel Ángel Porrúa, 1995, vol. III, pp. 225-264.

Reyes-VAlerio, Constantino, Arte Indocristiano. México, INAH, 2000. (Colección Obra Diversa)

Rubial GarcíA, Antonio, La hermana pobreza. El franciscanismo: de la Edad Media a la evangelización novohispana. México, FFL-UNAM, 1996. (Colección Seminarios)

SCHENONE, Héctor H., Iconografía del Arte Colonial. Los santos. Buenos Aires, Fundación Tarea, 1992, vols. I y II.

SEBASTIÁN, Santiago, Iconografía e Iconología del Arte Novohispano. Italia, Azabache, 1992. (Arte Novohispano, 6) TORquEMADA, fray Juan de, Monarquía Indiana. 4a. ed. México, Porrúa, 1969, 3 vols. (Biblioteca Porrúa, 41-43) Toussaint, Manuel, Arte Colonial en México. 5a. ed. MéxiCO, IIE-UNAM, 1990.

-, Pintura Colonial en México. 3a. ed. México,IIE-UNAM, 1990. 
